\title{
Determining the Soil Erodibility for an Experimental Basin in the Semi-Arid Region Using Geoprocessing
}

\author{
Erich Celestino Braga Pereira' ${ }^{1}$, Fernando Bezerra Lopes ${ }^{1}$, Francisco Emanoel Firmino Gomes ${ }^{1}$, \\ Aldênia Mendes Masceno de Almeida1, Ana Caroline Messias de Magalhães², \\ Eunice Maia de Andrade ${ }^{1}$
}

${ }^{1}$ Department Agricultural Engineering, Federal University of Ceará, Fortaleza, Brazil

${ }^{2}$ Department of Soil Science, Federal University of Ceará, Fortaleza, Brazil

Email: erichpos0@gmail.com, lopesfb@ufc.br, emanoelfg@hotmail.com, ald_m_m@hotmail.com, eandrade.ufc@gmail.com, ana_magalhaes@hotmail.com.br

How to cite this paper: Pereira, E.C.B., Lopes, F.B., Gomes, F.E.F., de Almeida, A.M.M., de Magalhães, A.C.M. and de Andrade, E.M. (2017) Determining the Soil Erodibility for an Experimental Basin in the Semi-Arid Region Using Geoprocessing. American Journal of Plant Sciences, 8, 3174-3188.

https://doi.org/10.4236/ajps.2017.812214

Received: October 3, 2017

Accepted: November 25, 2017

Published: November 28, 2017

Copyright $\odot 2017$ by authors and Scientific Research Publishing Inc. This work is licensed under the Creative Commons Attribution International License (CC BY 4.0).

http://creativecommons.org/licenses/by/4.0/

\begin{abstract}
Erosion is the natural process which has the greatest environmental impact, and is the principal trigger for desertification around the globe. The main model used to estimate soil loss by erosion is the Universal Soil Loss Equation (USLE), which unites the major factors that influence erosion into one equation. The soil erodibility factor $(\mathrm{K})$ is the component of this equation that represents soil physics, and is defined as the inherent capacity of the soil to withstand disintegration of its particles and their subsequent transport. The use of geostatistics is seen as an alternative in spatializing this variable from sampled to non-sampled points. The aim of this study therefore, was to determine the soil erodibility factor for an experimental basin in the semi-arid region of Brazil, in addition to generating the soil erodibility map using geostatistics. Disturbed and undisturbed soil samples were collected from 35 points, and laboratory samples were processed to determine the granulometry, permeability and organic matter of the soil, data which are used to determine the K-factor. Kriging was performed to spatialize the study variable, when spherical, exponential and Gaussian semivariograms were tested for generation of the soil erodibility map, these being evaluated by their respective deviations resulting from cross-validation. The mean value of $\mathrm{K}$ for the Haplic Luvisol was 0.0328 ton.ha.h/ha.MJ.mm; for the eutrophic Red-Yellow Argisol it was 0.0258 ton.ha.h/ha.MJ.mm; and for the Fluvic Neosol, it was 0.0424 ton.ha.h/ha.MJ.mm. The experimental basin is classified as highly erodible. The semivariogram that presented the best fit for generating the soil erodibility map of the study area was Gaussian.
\end{abstract}




\section{Keywords}

Erosion, Universal Soil Loss Equation, Geostatistics

\section{Introduction}

Erosion is the natural process of wear and entrainment of soil particles, and is occasioned by various factors, with water erosion being the principal cause [1]. Even when occurring naturally, erosion is caused by the anthropogenic actions of land use and occupation, this combination being the principal trigger for desertification around the globe [2].

In arid and semi-arid regions of the world, desertification is the natural process which has the greatest impact on increases in environmental degradation. According to [3], the process of desertification covers $25 \%$ of the Earth's surface, affecting about 2 billion people. Uncontrolled erosion reduces the biodiversity of ecosystems, negatively affects the water balance, and eliminates the friable layer of soil, drastically reducing agricultural production, and increasing pressure on other areas for the production of food and raw materials [4].

The main centres of desertification in Brazil are concentrated in the semi-arid region, located in the Northeast of the country. This tendency in the region is aided by natural conditions, such as a predominance of young soils, precipitation that is irregular and concentrated over both time and space, sparse vegetation, negative water balance, high temperatures, and intense rains [5].

In addition to natural conditions, anthropogenic activities such as the suppression of native vegetation, burning, intensive agriculture, and lack of conservation practices, favour the process of soil erosion and consequently desertification of the region, where water scarcity causes intense environmental and social problems [6].

The main model used to estimate erosion is the USLE (Universal Soil Loss Equation) [7], which includes the principal factors that affect erosion in the form of an equation [8]. Among these factors, the soil erodibility factor (K) is concerned with soil physics, and represents the inherent capacity of the soil to withstand the disintegration of its particles and their subsequent transport. In other words, this factor expresses the susceptibility of the soil to erosive processes [9]. According [10], the K factor is strongly correlated with soil loss and it is the key to predict the soil erosion.

In the field, the K-Factor can be obtained directly from a standard plot, or indirectly from empirical models. Due to the high costs involved in obtaining this factor directly, it is mainly determined through use of an empirical model, the Nomograph developed by [11], which associates soil organic matter, granulometry and permeability to determine the K-Factor [12].

According to [13], Geographic Information Systems (GIS) techniques in conjunction with models relating to soil loss, such as the USLE, have given excellent 
results in the prediction of soil loss, as well as the possibility of simulating different scenarios. According [14], GIS tools used together with geostatistical models favour more realistic modelling, once the error related to the process has been attributed.

According to [15], knowledge of the spatial distribution of soil erodibility is the principal mechanism for implementing practices aimed at controlling erosion. In this way, geostatistics is emerging as an alternative for the prediction of spatial variability in different environments, with the correlation of soil erodibility.

The aim of this study therefore, was to determine the soil erodibility factor for an experimental basin in the semi-arid region of Brazil, and to generate a soil erodibility map using geostatistics.

\section{Material and Methods}

The study area corresponds to the Curu Valley Experimental Basin (CVEB), in Pentecoste in the State of Ceará, Brazil. The site has a total area of $2.87 \mathrm{~km}^{2}$, located between $3^{\circ} 48^{\prime} 25^{\prime \prime}$ and $3^{\circ} 47^{\prime} 27^{\prime \prime} \mathrm{S}$, and $39^{\circ} 21^{\prime} 35^{\prime \prime}$ and $39^{\circ} 20^{\prime} 20^{\prime \prime} \mathrm{W}$. Within the CVEB is the Curu Valley Experimental Watershed (CVEW), a smaller experimental unit with $0.31 \mathrm{~km}^{2}$. The CEWB is a control basin where the hydrossedimentologal processes are evaluate with many equipments support installed, such as pluviographs, parshall gutters, a linigraph, erosion plots and thin-wallets structures. The location of the study area can be seen in Figure 1 .

The climate of the region is type BSw'h, hot and dry, according to the Köppen classification. The climate group is semi-arid, hot and dry, with rainfall concentrated from January to April. The average temperature is greater than $26^{\circ} \mathrm{C}$, with

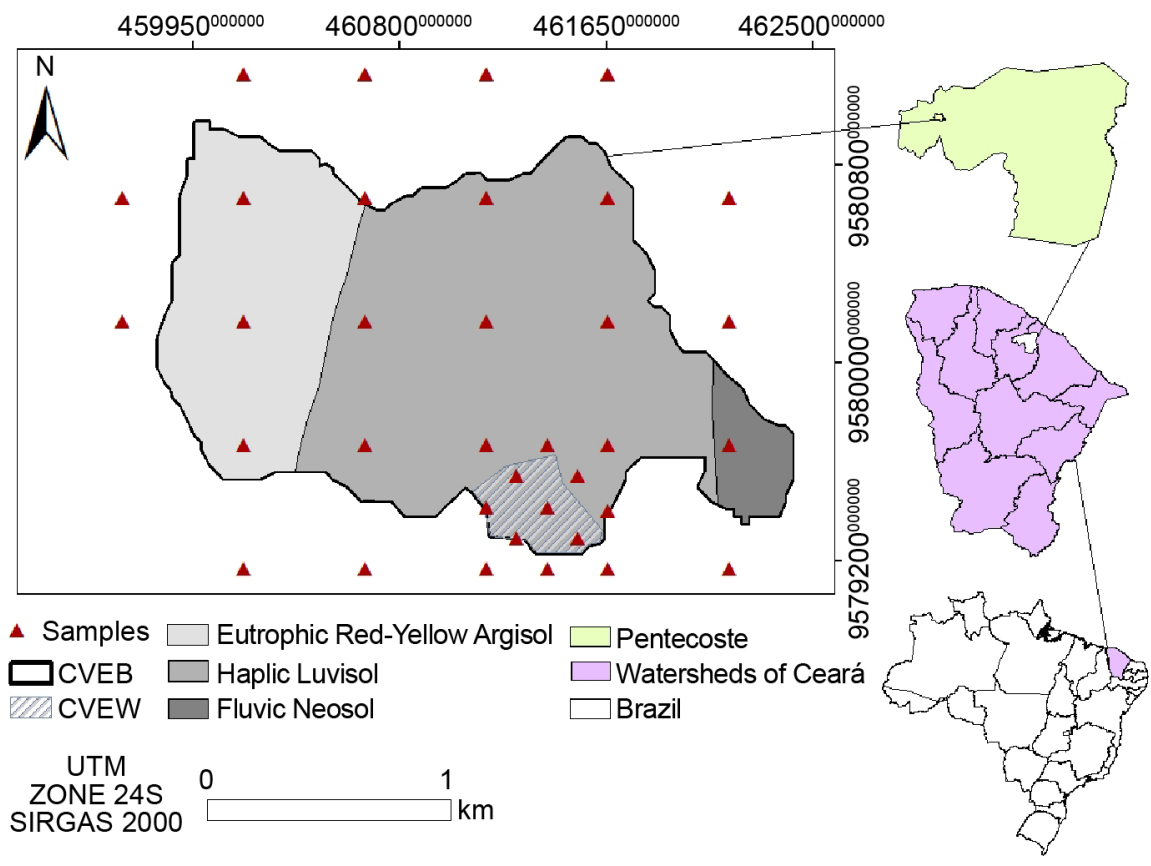

Figure 1. Location of the Curu Valley Experimental Basin (CVEB), Curu Valley Experimental Watershed (CVEW) and respective soil classes and soil collection points. 
an average rainfall of $706.6 \mathrm{~mm}$, a total Piche evaporation of $1536 \mathrm{~mm}$, and insolation of 2840.9 hours [16] [17].

The study area has three classes of soil, represented by a eutrophic Red-Yellow Argisol, Haplic Luvisol and Fluvic Neosol, as seen in Figure 1 [18]. The soil classes have been updated to the most recent classification of the Brazilian Soil Classification System [19].

The soil collection points were previously spaced on an equidistant digital grid representing the study area; in the CVEB the points on the grid were 500 metres apart, while in the CVEW, nine points were spaced 250 metres apart. There was a total of 35 points, as shown in Figure 1. We collect soils samples between January and March 2016.

Disturbed and undisturbed soil samples were taken from a depth of $0-20 \mathrm{~cm}$. For the undisturbed samples, a Uhland auger was used. The collection cylinders were fashioned from DN80 PN100 PVC pipe, and have a volume of $232.3 \mathrm{~cm}^{3}$, with a diameter of $6.5 \mathrm{~cm}$ and a height of $7 \mathrm{~cm}$. The undisturbed sample was used to determine soil permeability.

The disturbed samples were collected with the aid of a hoe in the vicinity of the undisturbed samples, and packed in plastic bags. These samples were used to determine the granulometry and organic matter of the soils.

Analysis of the soil samples was carried out at the Soil Mechanics and Pavements Laboratory (LMSP) of the Department of Hydraulic and Environmental Engineering (DEHA), the Federal University of Ceará (UFC). The particle-size analysis was prepared following [20], using the combined method of sedimentation and sieving. Segregation of the particles was as follows: Gravel (GV) from 4.8 to $76 \mathrm{~mm}$, Course Sand (CS) from 2 to $4.8 \mathrm{~mm}$, Medium Sand (MS) from 0.42 to $2 \mathrm{~mm}$, Fine Sand (FS) from 0.05 to $2 \mathrm{~mm}$, Silt (S) from 0.005 to $0.05 \mathrm{~mm}$, and Clay $(\mathrm{C})$ with values less of than $0.005 \mathrm{~mm}$ [21]. The results for granulometry were interpreted according [22], as shown in Table 1.

The values for soil organic matter were obtained from NBR 13600-Determining the organic matter content of the soil by burning at $440^{\circ} \mathrm{C}$ [23]. The organic matter content is given by Equation (1).

$$
\mathrm{OM}=\frac{1-\mathrm{B}}{\mathrm{A}} \times 100 \%
$$

where: $O M$ is the organic matter, $A$ is the weight of the sample (g) before burning, and B is the weight of the sample ( $\mathrm{g}$ ) after burning in a muffle furnace.

Values related to soil permeability were obtained from the undisturbed soil samples as per [24]_Determination of the permeability coefficient of variable-load clayey soils using a soil permeameter under varying conditions of hydraulic loading. The value obtained for permeability was classified according to Table 2.

The $\mathrm{K}$ factor was calculated for each of the 35 points sampled as per Equation (2), proposed by Wishmeier, Johnson and Cross [11]. 
Table 1. Structure class used in determination of the soil erodibility factor by Wishmeier, Johnson and Cross equation.

\begin{tabular}{ccc}
\hline$S$ & Granulometry* & Description \\
\hline 1 & $\mathrm{FS}^{1}+\mathrm{S}^{2}>50 \%$ & Very fine granular \\
2 & $\mathrm{C}^{3}+\mathrm{S}+\mathrm{FS}>50 \%$ & Fine granular \\
3 & $\mathrm{C}+\mathrm{S}+\mathrm{FS}+\mathrm{MS}^{4}+\mathrm{CS}^{5}>50 \%$ & Coarse granular \\
4 & $\mathrm{GV}^{6}>50 \%$ & Compact \\
\hline
\end{tabular}

"FS = Fine sand; $\mathrm{S}=$ Silt; $\mathrm{C}=$ Clay; $\mathrm{MS}=$ Medium sand; CS = Coarse sand; GV = Gravel; Adapted from [22].

Table 2. Soil permeability class in relation to hydraulic conductivity.

\begin{tabular}{ccc}
\hline P & Permeability $\left(\mathrm{mm} \cdot \mathrm{h}^{-1}\right)$ & Texture \\
\hline 1 & $>60$ & Sand \\
2 & $20-60$ & Loamy sandy, sandy loam \\
3 & $5-20$ & Loam, silt loam \\
4 & $2-5$ & Sandy clay loam, clay loam \\
5 & $1-2$ & Silty clay loam, sandy clay \\
6 & $<1$ & Silty clay, clay \\
\hline
\end{tabular}

Source: Adapted from [22].

$$
\mathrm{K}=\frac{0.1318 * 2.1 \mathrm{M}^{1,14}\left(10^{-4}\right)(12-\mathrm{MO})+3.25(\mathrm{~S}-2)+2.5(\mathrm{P}-3)}{100}
$$

where: $\mathrm{M}$ is the parameter related to the primary soil particles, and obtained by: $M=(F S+S)(100-C)$; where FS is fine sand, $S$ is silt, and C is clay, in percentage. $\mathrm{OM}$ is the Organic Matter; $\mathrm{S}$ is the parameter related to soil structure; $\mathrm{P}$ is the parameter related to soil permeability.

The values for erodibility were classified according to [25], who classified values lower than $0.0152 \mathrm{ton} \cdot \mathrm{ha} \cdot \mathrm{h} / \mathrm{ha} \cdot \mathrm{MJ} \cdot \mathrm{mm}$ as of low erodibility, values between 0.0152 and 0.0305 ton.ha.h/ha.MJ.mm as of moderate erodibility, and values greater than 0.0305 ton.ha.h/ha.MJ.mm as of high erodibility.

Descriptive statistics of the data were carried out, evaluating such variables as Minimum Value, Maximum Value, Mean and Coefficient of Variation (CV). The coefficient of variation was evaluated as per the [26] classification, where a of $\mathrm{CV}<12 \%$ classifies the coefficient of variation as low, $12 \%<\mathrm{CV}<60 \%$ classifies it as moderate, and CV $>60 \%$ classifies it as high.

The geostatistical kriging model was applied in order to observe the spatial dependence of the variable under study. The variables analysed for the semivariograms were Range (a), Nugget Effect (C0) and Sill (C1). The models tested were spherical, exponential and Gaussian. 
Spatial dependence was verified from the stationarity assumption of the intrinsic hypothesis for the adjusted semivariograms. According to [27] the semivariograms being tested, the Spherical, the Exponential and the Gaussian, are the main semivariograms used in kriging. Equations (3), (4) and (5) express the algorithms for these variograms.

$$
\begin{aligned}
& \text { a. Spherical: } g(h)=C 0+C 1\left[1.5(h / a)-0.5(h / a)^{3}\right], \\
& \qquad \operatorname{para} 0<\mathrm{h}<\mathrm{a} \text {; } g(h)=C 0+C 1 \text {, if } h>a \\
& \text { b. Exponential: } g(h)=C 0+C 1[-\exp (-3 h / a)], \text { for } 0<h<a \text {; } \\
& \text { c. Gaussian: } g(h)=C 0+C 1\left[1-\exp \left(-3 h^{2} / a^{2}\right)\right], 0<h<a
\end{aligned}
$$

where: $\mathrm{C} 0$ is the nugget effect; $\mathrm{C} 1$ is the contribution, or sill; $\mathrm{a}$ is the range; and $\mathrm{h}$ is the distance between observations.

The Degree of Spatial Dependence (DSD) was calculated according to Equation (6), proposed by [28].

$$
\mathrm{DSD}=\frac{\mathrm{C} 0}{\mathrm{C} 0+\mathrm{Cl}} \times 100
$$

where: $\mathrm{C} 0$ is the nugget effect; and $\mathrm{C} 1$ is the sill (or contribution).

The DSD was classified according to [28]: DSD $<25 \%$, the semivariogram has strong spatial dependence; $25 \% \leq \mathrm{DSD} \leq 75 \%$, the semivariogram has moderate spatial dependence; and a DSD > 75\% indicated weak spatial dependence.

The semivariogram was chosen as per [29], who proposed that when evaluating the cross-validation data of the models, the mean error of the semivariogram should be close to zero (0), the root mean square error, should be close to one (1), and the standard error of the mean and root mean square error should have similar values that are as small as possible.

\section{Results and Discussion}

The results of the variables used to obtain the K factor for the Haplic Luvisol, the eutrophic Red-Yellow Argisol and the Fluvic Neosol at the deep $0.20 \mathrm{~m}$ can be seen in Table 3.

From the results of Table 3 about Haplic Luvisol, it can be seen that the primary soil particles (clay, silt and fine sand) account for on average $56.2 \%$ of the total soil granulometry, while the heavier material (gravel, and coarse and medium sand), which has a consequently greater capacity to withstand the erosive processes, makes up $43.8 \%$. These values demonstrate the predominance of fine material in the soil in relation to coarser material, leaving a greater percentage of erodible material available for erosion.

The average percentage of clay in the composition of the primary soil particles is about $22 \%$ of the total (Table 3). For this class of soil, the clay is concentrated in the subsurface, in the Bt horizon, which reduces the permeability of water in the soil, and influences both saturation of the overlying horizons and surface flow [30].

Aggregation in this surface layer has its structure improved by soil organic 
Table 3. Descriptive statistics (D), Organic matter content (OM), granulometric fractions, structure class (S) and permeability class (P) for the Haplic Luvisol, eutrophic Red-Yellow Argisol and Fluvic Neosol.

\begin{tabular}{|c|c|c|c|c|c|c|c|c|c|c|c|c|}
\hline \multirow{2}{*}{$\mathrm{D}^{1}$} & \multicolumn{4}{|c|}{ HAPLIC LUVISOL } & \multicolumn{4}{|c|}{ EUTROPHIC RED-YELLOW ARGISOL } & \multicolumn{4}{|c|}{ FLUVIC NEOSOL } \\
\hline & Min & $\operatorname{Max}$ & Mean & $\mathrm{CV}$ & Min & Max & Mean & $\mathrm{CV}$ & Min & $\operatorname{Max}$ & Mean & $\mathrm{CV}$ \\
\hline$\% \mathrm{GV}^{2}$ & 0.04 & 74.47 & 21.73 & 122.4 & 0.8 & 52.08 & 23.63 & 94.7 & 0.07 & 27.31 & 12.67 & 115.2 \\
\hline$\% \mathrm{CS}^{3}$ & 1.13 & 21.61 & 6.1 & 92.9 & 1.98 & 10.27 & 6.72 & 44.2 & 1.45 & 6.5 & 3.74 & 58.9 \\
\hline$\% \mathrm{MS}^{4}$ & 3.23 & 32.01 & 15.97 & 45.7 & 8.53 & 32.63 & 20.3 & 37.3 & 13.38 & 33.42 & 20.85 & 44.2 \\
\hline$\% \mathrm{FS}^{5}$ & 5.77 & 60.51 & 34.37 & 55.2 & 16.86 & 47.6 & 26.79 & 36 & 21.51 & 58.35 & 42.71 & 42.9 \\
\hline$\% S^{6}$ & 1.06 & 20.25 & 9.59 & 56.2 & 3.91 & 18.57 & 11.15 & 46.7 & 5.38 & 15.7 & 11 & 43.9 \\
\hline$\% \mathrm{C}^{7}$ & 3.88 & 26.74 & 12.24 & 46.5 & 4.57 & 28.27 & 11.41 & 66.3 & 5.88 & 11.47 & 9.02 & 26.5 \\
\hline$\% S+\mathrm{FS}^{8}$ & 10.6 & 69.97 & 43.96 & 47.8 & 23.65 & 62.38 & 37.93 & 33.5 & 26.89 & 74.04 & 53.71 & 39.2 \\
\hline$\% \mathrm{OM}^{9}$ & 0.6 & 10.45 & 4.62 & 61.1 & 2.8 & 7.67 & 4.43 & 31.8 & 2.08 & 4.42 & 2.85 & 37.2 \\
\hline $\mathrm{M}^{10}$ & 1012 & 6465.7 & 3817.4 & 48.1 & 2193.4 & 5513.5 & 3328.8 & 32.1 & 2531 & 6765.8 & 4867.9 & 38.8 \\
\hline$S^{11}$ & 2 & 4 & 3 & 27.2 & 2 & 4 & 3 & 27.8 & 2 & 3 & 2 & 25 \\
\hline $\mathrm{P}^{12}$ & 2 & 5 & 4 & 22.7 & 2 & 4 & 3 & 22.2 & 3 & 5 & 3 & 33.3 \\
\hline
\end{tabular}

${ }^{1} \mathrm{D}=$ Statistic $;{ }^{2} \mathrm{GV}=$ Gravel; ${ }^{3} \mathrm{CS}=$ Coarse sand; ${ }^{4} \mathrm{MS}=$ Medium sand; ${ }^{5} \mathrm{FS}=$ Fine sand; ${ }^{6} \mathrm{~S}=$ Silt $;{ }^{7} \mathrm{C}=$ Clay; ${ }^{8} \mathrm{~S}+\mathrm{FS}=$ Silt + Fine sand $;{ }^{9} \mathrm{OM}=$ Organic matter; ${ }^{10} \mathrm{M}=(\mathrm{FS}+\mathrm{Silt})\left(100\right.$ - Clay); ${ }^{11} \mathrm{~S}=$ Structure class; ${ }^{12} \mathrm{P}=$ Permeability class. Min (minimum); Max (maximum); CV (coefficient of variation).

matter (SOM), which had an average value of 4.62\% SOM. For [31], the organic matter content in tropical soils varies from $1 \%$ to $5 \%$, clearly demonstrating that the contribution of this component presented high values in this study.

The Haplic Luvisol had the highest values for CV among the three soils under study. The high variability is influenced due to this class occurring in hilly terrain, consisting of some areas where there is displacement of the soil particles, and other areas where there is deposition, reducing the uniformity of particle size distribution in the surface layer of the soil.

Evaluating Red-Yellow Argisol (Table 3), it can be seen that the mean percentage distribution of the primary soil particles and particles of larger diameter are equal to $49.34 \%$ and $50.66 \%$ respectively. Equivalent participation by the larger-diameter particles weakens any susceptibility to erosion, since these particles resist entrainment due to their greater weight compared to the primary soil particles.

A reduced average value for $\mathrm{M}(3328.8)$ can be seen in Table 3 for the eutrophic Red-Yellow Argisol in relation to the other soil classes. This reduced value is a result of the low concentration of primary particles in the surface layer of this soil, which limits its predisposition to erosive processes.

The organic matter in this class of soil strongly influences structure, having an average of $4.43 \%$, which is considered a high value for SOM. For [32] the structural effect of organic matter is greater in soils with a clay content of less than $25 \%$. The SOM therefore strongly favours structuring in this class of soil, since the percentage of clay is only $11.41 \%$ (Table 3 ).

In relation to $\mathrm{CV}$, this class of soil had the lowest values for the three soil 
classes under study, with only two variables where the values for CV were classified as high, $94.74 \%$ and $66.32 \%$ for the gravel and clay respectively (CV $>60 \%$ ), while the other variables displayed moderate values for $\mathrm{CV}(12 \%<\mathrm{CV}<60 \%)$. According to [30], stoniness is not an inherent characteristic of this class of soil, which explains the high CV value for the variable, gravel.

The mean value for granulometry for the Fluvic Neosol (Table 3) shows a particle-size distribution of $63 \%$ of the total composition of the soil, made up of primary soil material, with only $37 \%$ remaining for the coarser soil particles such as gravel, and coarse and medium sand. This composition, with a predominance of fine material, favours entrainment of the particles by the process of erosion.

Among the primary soil particles, fine sand and silt make up around $86 \%$ of the total fine material, while clay accounts for only $14 \%$ of this total, culminating in the highest mean value for $M$ (4867.9). This lesser predominance of clay in the surface horizon, in relation to the other primary soil particles, reduces particle aggregation, and more strongly advances entrainment which, due to the predominance of small-diameter particles, would already show a tendency to be high.

According to [30], the stratification of organic matter at depth occurs in a fairly variable way in the soil profile, since this soil component is input together with particles entrained during the deposition process. Thus, the average value of $2.8 \%$ for organic matter does not favour aggregation enough of the soil particles to compensate the low soil structure, since the evolution of layers in this soil is not related to soil genesis, but to the contribution of more elevated regions of the terrain.

The variables analysed in the Fluvic Neosol displayed greater values for CV than in the eutrophic Red-Yellow Argisol, even with only one variable with a high CV, represented by the gravel with $115.24 \%$ (CV > 60\%). As this is a soil formed by the deposition of fluvial sediments, the soil class displays high variability in particle size, since stratification of the sediments that are input in the lowest area of terrain occurs heterogeneously, not following a soil genesis pattern as the both others soils studied.

Table 4 shows the values for erodibility of the classes of soil under study.

The mean value for soil erodibility in the Haplic Luvisol seen in Table 4 was 0.0328 ton.ha.h/ha.MJ.mm classifying according to [25] as highly erodible. [33] found a value for $\mathrm{K}$ of 0.0420 ton.hah/ha·MJ.mm for this class of soil, while [34], evaluating a Chromic Luvisol found values for $\mathrm{K}$ of 0.0313 and 0.0353 ton.ha.h/ha.M.mm, agreeing with the high values for soil erodibility of this class of soil.

The high values for $\mathrm{K}$ observed for the Haplic Luvisol, are related to the low aggregation of the A horizon, which is expressed in the high average value for $\mathrm{M}$, of the order of 3817.4 (Table 3); further, the class 3 soil structure (S) (coarse granular, Table 3$)$, and the mean value for class 4 permeability $(2<\mathrm{P}<5$ $\mathrm{mm} \cdot \mathrm{h}^{-1}$, Table 3 ) give values that positively increment the equation for soil 
Table 4. Statistics, occurrence of soil classes, values for soil erodibility (K) and classification of the erodibility and coefficient of variation $(\mathrm{CV})$.

\begin{tabular}{|c|c|c|c|c|}
\hline \multirow{2}{*}{ Soil } & \multirow{2}{*}{ Occurrence (\%) } & \multirow{2}{*}{$S$} & K & \multirow{2}{*}{ Classification } \\
\hline & & & (ton.ha.h/ha.MJ.mm) & \\
\hline \multirow{4}{*}{ HL } & \multirow{4}{*}{65.94} & Min & 0.0098 & Low \\
\hline & & $\operatorname{Max}$ & 0.0673 & High \\
\hline & & Mean & 0.0328 & High \\
\hline & & $\mathrm{CV}$ & 52.96 & Moderate \\
\hline \multirow{4}{*}{ RYAe } & \multirow{4}{*}{29.16} & Min & 0.0127 & Low \\
\hline & & Max & 0.0344 & High \\
\hline & & Mean & 0.0258 & Moderate \\
\hline & & $\mathrm{CV}$ & 25.19 & Moderate \\
\hline \multirow{4}{*}{ FN } & \multirow{4}{*}{4.9} & Min & 0.0317 & High \\
\hline & & $\operatorname{Max}$ & 0.0535 & High \\
\hline & & Med & 0.0424 & High \\
\hline & & $\mathrm{CV}$ & 24.6 & Moderate \\
\hline Total & 100 & & $0.0312^{*}$ & High \\
\hline
\end{tabular}

$\mathrm{HL}=$ Haplic Luvisol; RYAe = eutrophic Red-Yellow Argisol; FN = Fluvic Neosol. $\mathrm{S}=$ Statistic; $\mathrm{K}=$ Soil erodibility factor. Min (minimum); Max (maximum) and CV (coefficient of variation). ${ }^{*}$ Weighted mean between the mean values for erodibility and the area occupied by soil class.

erodibility. The value for organic matter of $4.62 \%$ (Table 3 ) in this class of soil reduced the erodibility value, but not by enough to alter its classification of high erodibility.

For the eutrophic Red-Yellow Argisol, Table 6 shows a mean value for soil erodibility of 0.0258 ton.ha.h/ha.MJ.mm, classifying this soil class as moderately. [35] published values for this class that ranged from 0.0280 to 0.0430 ton.ha.h/ha.MJ.mm, [36] found a value of 0.0260 ton.ha.h/ha.MJ.mm, while [37] obtained a value of 0.0400 ton.ha.h/ha.MJ.mm, classifying this class of soil as moderately to highly erodible. According to [38], this is an order that shows a predisposition to erosive processes which depends on the position of the incremental layer of clay in the subsurface, since this textural gradient does not favour subsurface infiltration, favouring instead saturation of the surface layer and causing flash flooding.

The reduced mean value for $\mathrm{M}$ (3328.8) seen in Table 3, favoured a reduction in the erodibility value of this class of soil. In addition, the high value for organic matter, with a concentration of $4.43 \%$, reduces the erodibility value. Another variable to favour a reduction in the $\mathrm{K}$ factor was the class of permeability (class 3 - permeability ranging from 5 to $20 \mathrm{~mm} \cdot \mathrm{h}^{-1}$ ) (Table 3), which favours the water permeability and reduces the runoff, reducing the $\mathrm{K}$ value.

For the Fluvic Neosol, the mean value for the soil erodibility factor was 0.0424 ton.ha.h/ha.MJ.mm (Table 4), classifying the soil as highly erodible. [39] found 
an erodibility factor of 0.0350 ton.ha.h/ha.MJ-mm; [40], found a factor of 0.0460 ton.ha.h/ha.MJ.mm. All these values classify this class of soil as highly erodible.

The high values found for soil erodibility, occur due to the smaller structuring of the Fluvic Neosol, with a high value for M (4867.9) (Table 3). This high value for M classified the Fluvic Neosol as the most erodible soil class among the three classes of soils under study. When evaluating the weighted mean of the values for soil erodibility $(\mathrm{K})$ in relation to the area occupied by each of the classes, a mean value for erodibility of $0.0312 \mathrm{ton} \cdot \mathrm{ha} \cdot \mathrm{h} / \mathrm{ha} \cdot \mathrm{MJ} \cdot \mathrm{mm}$ is found, classifying the Curu Valley Experimental Basin as highly erodible.

It can be seen in Table 4 that the three classes of soil have values for the coefficient of variation that are classified as moderate $(12 \%<\mathrm{CV}<60 \%)$. The greatest variation in the values for soil erodibility was seen in the Haplic Luvisol, with a CV of 52.96\%, followed by the eutrophic Red-Yellow Argisol with a CV of $25.19 \%$; the smallest variations were seen in the FluvicNeosol, with a CV of $24.60 \%$.

The Figure 2 shows the variograms of the three models studied. The components of the semivariograms under study, as well as the Degree of Spatial Dependence, can be seen in Table 5. The DSD obtained for the Gaussian semivariogram was $21.49 \%$, for the spherical semivariogram it was $23.42 \%$, and for the exponential it was $25.69 \%$, demonstrating that in this study the variable of soil erodibility displays weak spatial dependence.

Table 6 presents data from cross-validation of the models, which is the technique employed to extract a sampled piece of data and estimate it using the semivariogram, showing the deviations for the models under study.

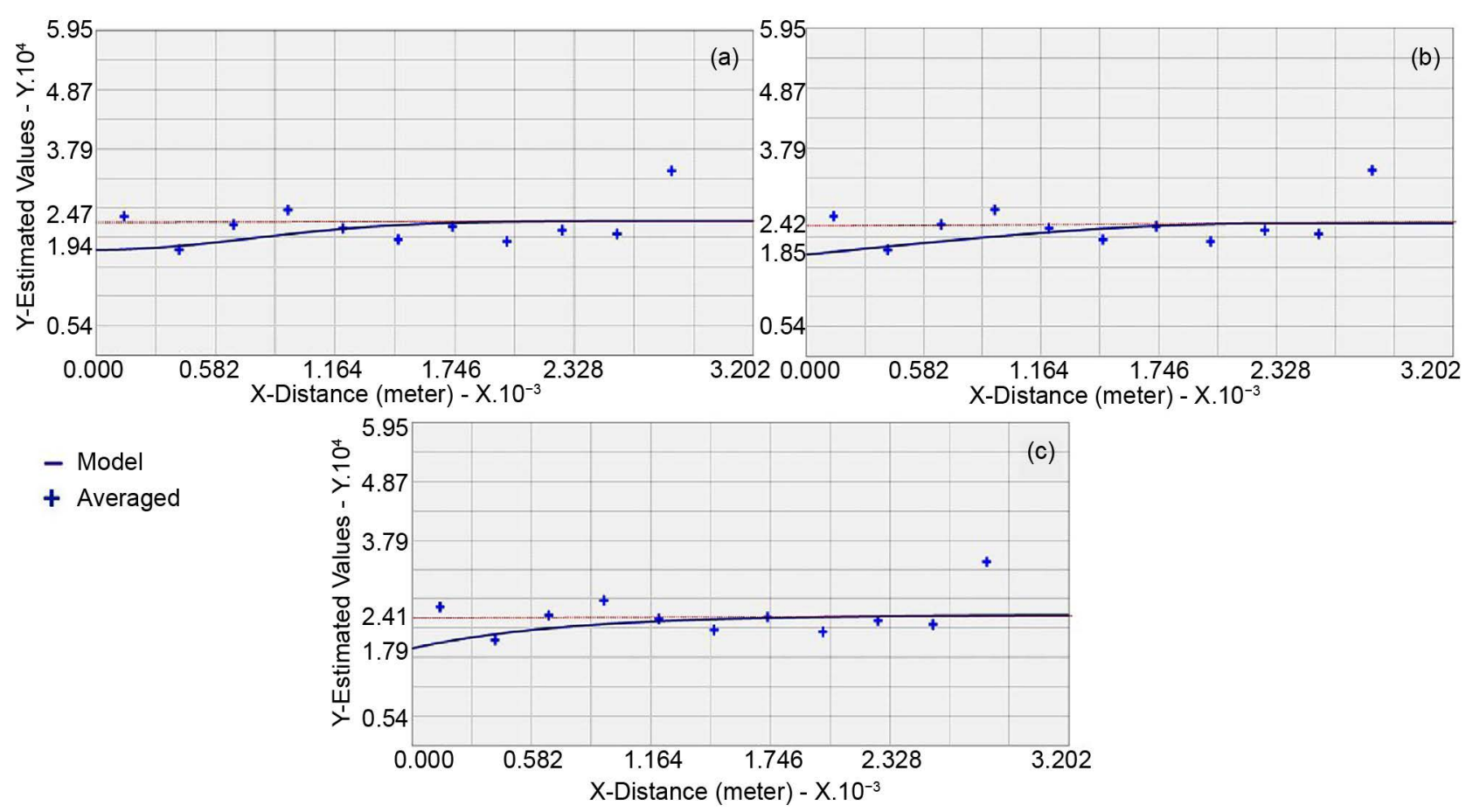

Figure 2. Variogram Gaussian (a), Spherical (b) and Exponential (c). 
Table 5. Variogram components and Degree of Spatial Dependence (DSD).

\begin{tabular}{ccccc}
\hline Variogram & Nugget Effect $\left(c_{0}\right)$ & Sill $\left(c_{1}\right)$ & Range m (a) & DSD (\%) \\
\hline Spherical & $5.66 \times 10^{-5}$ & $1.85 \times 10^{-4}$ & 1073.06 & 23.42 \\
Exponential & $6.19 \times 10^{-5}$ & $1.79 \times 10^{-4}$ & 1073.06 & 25.69 \\
Gaussian & $5.31 \times 10^{-5}$ & $1.94 \times 10^{-4}$ & 1073.06 & 21.49 \\
\hline
\end{tabular}

Table 6. Statistics of the error generated by cross-validation of the models.

\begin{tabular}{ccccc}
\hline Variogram & MeanError & $\begin{array}{c}\text { Standard root mean } \\
\text { square error }\end{array}$ & $\begin{array}{c}\text { Standard error } \\
\text { of the mean }\end{array}$ & $\begin{array}{c}\text { Root mean } \\
\text { square error }\end{array}$ \\
\hline Spherical & -0.00079 & 0.95 & 0.0150 & 0.0142 \\
Exponential & -0.00067 & 0.93 & 0.0152 & 0.0142 \\
Gaussian & -0.00063 & 0.94 & 0.0149 & 0.0141 \\
\hline
\end{tabular}

The Gaussian semivariogram was the most suitable model for evaluating the cross-validation (Table 6), as its value for mean error was closer to zero, the standard root mean square error was closer to 1 , the standard error of the mean and the root mean square error were smaller, thereby fitting the requirements of [29].

For the Gaussian Semivariogram, which was chosen, the Nugget Effect (C0) was $1.94 \times 10^{-4}$, the Sill (C1) was $5.305 \times 10^{-5}$, and the Range (a) was 1073 metres. The Sill (C1) is the semivariogram component that expresses the value from the nugget effect up to the value for Range (a). The sum of the Nugget Effect (C0) and the Sill (C1), with a value of $2.47 \times 10^{-4}$, shows the value for a variogram that reaches a range (a) of 1073 metres, and represents the limit up to which a correlation exists between the points; within that limit, interpolations occur at distances less than the spacing between the points.

According to [41], values located at distances of less than the range (a) show spatial dependence, allowing for interpolations at distances less than the sample spacing.

As the range (a) illustrates the limit below which values are interpolated at distances of less than those of the grid, for values estimated at distances greater than 1073 metres, the variable was interpolated from the grid spacing, with values being estimated up to a maximum distance of 3201 metres.

The soil erodibility map, interpolated by the geostatistical method of Kriging using the Gaussian semivariogram, can be seen in Figure 3.

When evaluating the map relative to soil erodibility, it can be seen that the lowest values for erodibility, with a modelled value varying from 0.0221 to 0.0251 ton.ha.h/ha.MJ.mm, occur in the lightest area of the map, located in the region west of the basin. The eutrophic Red-Yellow Argisol is representative of this region west of the basin. This modelling demonstrates what was shown in Table 6, with this class of soil displaying the lowest mean value for erodibility among the three classes studied, of the order of 0.0258 ton.ha.h/ha.MJ.mm. 


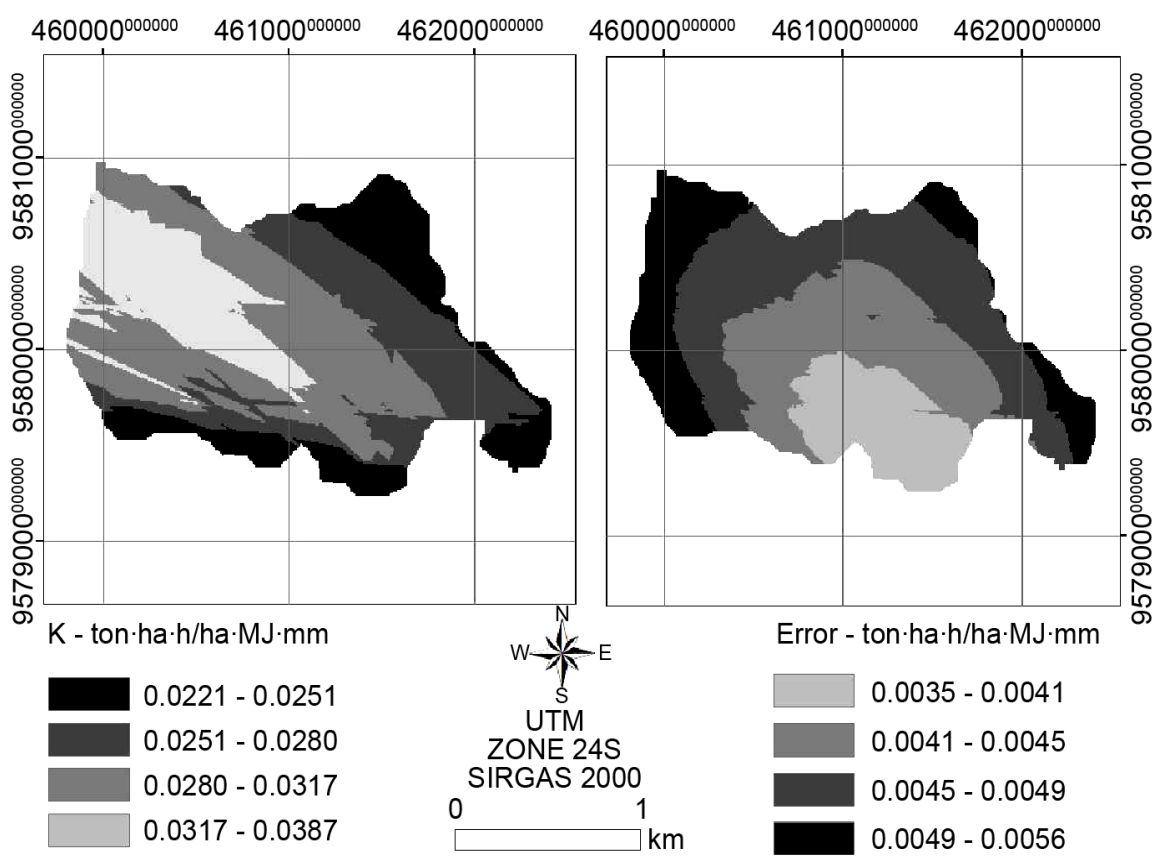

Figure 3. Soil erodibility map and modelling error map for the Curu Valley Experimental Basin.

The greatest values for erodibility were seen in the extreme northeast, south and west (dark area on the map), with values ranging from 0.0317 to 0.0387 ton.ha.h/ha.MJ.mm, these areas mainly being represented by the Haplic Luvisol and the FluvicNeosol.

Greater modelling errors can be seen in the extreme regions of the map, except in the area further to the south (lightest region), demonstrating that the smaller the sampled point cloud, the greater the errors in interpolating of the variable.

\section{Conclusions}

The Curu Valley Experimental Basin was classified as highly erodible, with the Haplic Luvisol and the Fluvic Neosol classified as soils of high erodibility.

The class of eutrophic Red-Yellow Argisol was classified as moderately erodible.

The Gaussian model was the semivariogram with the best fit for modelling the erodibility map for the Curu Valley Experimental Basin.

The lowest kriging errors were observed in the Curu Valley Experimental Watershed (CVEW), where the soils samples were collected at distance of 250 meters.

For a better interpolation of the soil erodibility variable, a greater number of soils samples are necessary for increasing the interpolation precision.

Soils samples at the depth greater than 0.20 meters are necessary to explain the soils characteristics evolution and how the variables occur that affects the soil erodibility in depth. 


\section{Acknowledgements}

The authors acknowledge for financial support and the Coordination for the Improvement of Higher Education Personnel (CAPES), Cearense Foundation of Scientific and Technological Support (FUNCAP) and National Council for Scientific and Technological Development (CNPq).

\section{Conflicts of Interest}

There are no conflicts of interest in present study.

\section{References}

[1] Santos, J.C.N., Andrade, E.M., Medeiros, P.H.A., Guerreiro, M.J.S. and Palácio, H.A.Q. (2017) Land Use Impact and Soil Erosion at Different Scales in the Brazilian Semi-Arid. Revista Ciência Agronômica, 48, 251-260. https://doi.org/10.5935/1806-6690.20170029

[2] Chang, I., Prasidhi, A.K., Im, J., Shin, H.D. and Cho, G.C. (2014) Soil Treatment Using Biopolymers for Anti-Desertification Purposes. Geoderma, 253-254, 39-47. https://doi.org/10.1016/j.geoderma.2015.04.006

[3] D’Odorico, P., Bhattachan, A., Davis, K.F., Ravi, S. and Runyan, C.W. (2013) Global Desertification: Drivers and Feedbacks. Advances in Water Resources, 51, 326-344. https://doi.org/10.1016/j.advwatres.2012.01.013

[4] Debolini, M., Schoorl, J.M., Temme, A., Galli, M. and Bonari, E. (2013) Changes in Agricultural Land Use Affecting Future Soil Distribution Patterns: A Case Study in Southern Tuscany (Italy). Land Degradation \& Development, 26, 574-586. https://doi.org/10.1002/ldr.2217

[5] Bronstert, A., Araújo, J.C., Batalha, R.J., Costa, A.C., Delgado, J.M., Francke, T., Foerster, S., Guentner, A., López-Tarazón, J.A., Mamede, G.L., Medeiros, P.H., Mueller, E. and Vericat, D. (2014) Process-Based Modeling of Erosion, Sediment Transport and Reservoir Siltation in mesoscale Semi-Arid Catchments. Journal of Soils and Sediments, 14, 2001-2018. https://doi.org/10.1007/s11368-014-0994-1

[6] Ferreira, A.C.C., Leite, L.F.C., Araújo, A.S.F. and Eisenhauer, N. (2014) Land-Use Type Effects on Soil Organic Carbon and Microbial Properties in a Semi-Arid Region of Northeast Brazil. Land Degradation \& Development, 27, 171-178. https://doi.org/10.1002/ldr.2282

[7] Wischmeier, W.H. and Smith, D.D. (1965) Predicting Rainfall Erosion Losses from Cropland East of the Rocky Mountains: A Guide for Selection of Practices for Soil and Water Conservation. US Government Printing Office, Washington DC.

[8] Aerswald, K., Fiener, P., Martin, W. and Elhaus, D. (2014) Use and Misuse of the K Factor Equation in Soil Erosion Modeling: An Alternative Equation for Determining USLE Nomograph Soil Erodibility Values. Catena, 118, 220-225. https://doi.org/10.1016/j.catena.2014.01.008

[9] Shabani, F., Kumar, L. and Esmaeili, A. (2014) Improvement to the Prediction of the USLE K Factor. Geomorfology, 204, 229-234. https://doi.org/10.1016/j.geomorph.2013.08.008

[10] Imani, R., Ghasemieh, H. and Mirzavand, M. (2014) Determining and Mapping Soil Erodibility Factor (Case Study: Yamchi Watershed in Northwest of Iran). Open Journal of Soil Science, 4, 168-173. https://doi.org/10.4236/ojss.2014.45020

[11] Wischmeier, W.H., Johnson, C.B. and Cross, B.V. (1971) A Soil Erodibility Nomo- 
gram for Farmland and Construction Sites. Journal of Soil and Water Conservation, 26, 189-193.

[12] Panagos, P., Meusburguer, K., Ballabio, C., Borreli, P. and Alewell, C. (2014) Soil Erodibility in Europe: A High-Resolution Dataset Based on LUCAS. Science of the Total Environment, 479-480, 189-200. https://doi.org/10.1016/j.scitotenv.2014.02.010

[13] Matheus, C.R. and Norton, M.S. (2013) Comparison of Pond-Sedementation Data with a GIS-Based USLE Modelo of Sediment Yield for a Small Forested Urban Watershed. Antropocene, 2, 89-101. https://doi.org/10.1016/j.ancene.2013.10.003

[14] Saygin, S.D., Ozcan, A.U., Basaran, M., Timur, O.B., Dolarslan, M., Yilman, F.E. and Erpul, G. (2014) The Combined RUSLE/SDR Approach Integrated with GIS and Geoestatistics to Estimate Annual Sediment Flux Rates in the Semi-Arid Catchment, Turkey. Environmental Earth Sciences, 71, 1605-1618. https://doi.org/10.1007/s12665-013-2565-y

[15] Addis, H.K. and Klik, A. (2015) Predicting the Spatial Distribution of Soil Erodibility Factor Using USLE Nomograph in an Agricultural Watershed, Ethiopia. International Soil and Water Conservation Research, 3, 282-290. https://doi.org/10.1016/j.iswcr.2015.11.002

[16] Aguiar, M.D.J.N., Viana, T.V.A., Aguiar, J.V., Lima, J.B., Crisóstomo Júnior, R.R., Aquino, F.C., Barreto Júnior, J.H.C. and Carneiro, F.A. (2002) Climatological Data of Pentecoste. Embrapa Agroindústria Tropical, 87, 6-17.

[17] FUNCEME Foundation of Meteorology and Water Resources. Historic Series. http://www.funceme.br

[18] CPRM Geologic Service of Brazil. Soil Map. http://www.cprm.gov.br

[19] EMBRAPA Brazilian Agricultural Research Corporation (2013) Brazilian Soil Classification System. 3rd Edition, EMBRAPA-SPI, Rio de Janeiro.

[20] NBR 7181 Brazilian Regulatory Standard (1984) Granulometric Analysis. ABNT, Rio de Janeiro.

[21] Pinto, C.S. (2000) Basic Course of Mecanic Soils. 3rd Edition, Oficina de Textos, São Paulo.

[22] Renard, K.G., Foster, G.R., Weesies, G.A., Mccool, D.K. and Yoder, D.C. (1997) Predicting Soil Erosion by Water: A Guide to Conservation Planning with the Revised Universal Soil Loss Equation (RUSLE). US Government Printing Office, Washington DC.

[23] NBR 13600 Brazilian Regulatory Standard (1996) Determination of Organic Matter Content by Igniting at $440^{\circ} \mathrm{C}$. ABNT, Rio de Janeiro.

[24] NBR 14545 Brazilian Regulatory Standard Determination of the Coefficient of Permeability of Clay Soils by a Falling. ABNT, Rio de Janeiro.

[25] Carvalho, N.O. (1994) Pratical Hidrossedimentology. CPRM, Rio de Janeiro.

[26] Warrick, A.W. and Nielsen, D.R. (1980) Spatial Variability of Soil Physical Properties in the Field. In: Hillel, D., Ed., Applications of Soil Physics, Academic Press, New York. https://doi.org/10.1016/B978-0-12-348580-9.50018-3

[27] Seidel, E.J. and Oliveira, M.S. (2013) Proposal of a Generation for Exponential and Gaussian Semivariogram Models. Semina: Ciências Exatas e Tecnológicas, 34, 125-132. https://doi.org/10.5433/1679-0375.2013v34n1p125

[28] Combardella, C.A., Moorman, T.B., Parkin, T.B., Karlen, D.L., Novac, J.M., Turco, R.F. and Konopka, A.E. (1994) Field-Scale Variability of Soil Properties in Central Iowa Soils. Soil Science Society of America Journal, 58, 1501-1511. 
https://doi.org/10.2136/sssaj1994.03615995005800050033x

[29] Mello, Y.R. and Oliveira, T.M.N. (2016) Statistical and Geostatistical Analysis of the Average Rainfall in the Municipality of Joinville (SC). Revista Brasileira de Meteorologia, 31, 229-239.

[30] FUNCEME Foundation of Meteorology and Water Resources (2012) Recognition Survey of Medium Intensity of Soils of Ceara Southern Meso Region. FUNCEME, Fortaleza.

[31] Teixeira, W.G., Kern, D.C., Madari, B.E., Lima, H.N. and Woods, W. (2009) The Indians Blackland sof Amazonia: Their Characterization and Use of This Knowledge in the Creationof New Areas Embrapa Amazônia Ocidental, Manaus. http://www.alice.cnptia.embrapa.br/alice/handle/doc/684554

[32] Amaro Filho, J., Assis Júnior, R.N. and Mota, J.C.A. (2008) Soils Physics: Concepts and Application. ImprensaUniversitária, Fortaleza.

[33] Silva, M.S., Paiva, F.M.L. and Santos, C.A.G. (2009) Evaluation of Soil Erodibility and Soil Loss in Capiá Basin Based on Geographical Information System and Remote Sensing. Revista Brasileira de Geografia Física, 2, 26-40.

[34] Mannigel, A.R., Passos, M., Moreti, D. and Mederiros, L.R. (2002) Erodibility Fator and Soil Loss Tolerance in the Stateof São Paulo Acta Scientiarum, 24, 1335-1340. https://doi.org/10.4025/actasciagron.v24i0.2374

[35] Bertoni, J. and Lombardi Neto, F. (2008) Soil Conservatio. 7th Edition, EditoraÍcone, São Paulo.

[36] Serio, J., Costa, C.A.G., Teixeira, A.S. and Ortega, E. (2008) USLE and GIS Application in the Characterization of Three Micro Basins in Brazil. Ciências Agrárias e Ambientais, 6, 213-221.

https://periodicos.pucpr.br/index.php/cienciaanimal/article/view/10484

[37] Corrêa, E.A., Moraes, I.C. and Pinto, S.A.F. (2015) Erodibility Estimation and Tolerance of Soil Loss in Center East Paulista Region Geociências, 34, 848-860.

[38] Lepsch, I.F. (2011) 19 Pedology Lessons. Oficina de Textos, São Paulo.

[39] Oliveira, F.G., Seraphim, O.J. and Borja, M.E.L. (2015) Soil Loss Estimation and Natural Erosion Potential of the Lageado Hydroelectric Power Plant Basin, Botucatu, SP. Revista Energiana Agricultura, 30, 302-309. https://doi.org/10.17224/EnergAgric.2015v30n3p302-309

[40] Farinasso, M., Carvalho Júnior, O.A., Guimarâes, R.F., Gomes, R.A.T. and Ramos, V.M. (2006) Qualitative Evaluation of the Laminar Erosion Potential in Large Areas through the EUPS-Universal Soil Loss Equation Using New GIS Methodologies for the Calculation of Its Factors in the Alto Parnaíba Region-PI-MA. Revista Brasileira de Geomorfologia, 7, 73-85. https://doi.org/10.20502/rbg.v7i2.80

[41] Mantovanelli, B.C., Campos, M.C.C., Alho, L.C., Franciscon, U., Nascimento, M.F. and Santos, L.A. (2016) Spatial Distribution of Soil Acidity Components in Natural Field Area in the Region of Humaitá, Amazonas Revista de Ciências Agroambientais, 14, 1-9. 